\title{
Immunohistochemical features of extra-nodal NK/T cell lymphoma
}

Type: Meeting Abstract

Content:

NK/T cell lymphoma is a destructive extranodal lymphoproliferative disorder of a putative natural killer (NK) cell lineage. This rare malignant lymphoma is difficult to diagnose due to the histological resemblance to reactive processes hence was once considered as an inflammatory lesion known as lethal midline granuloma or non-healing granuloma. Providentially, the advance in immunophenotyping has permit characterization of NK/T-cell lymphoma, as a distinct entity from other type of lymphoma. It is most commonly involved the nasal cavity, paranasal sinuses and hard palate and as the case we reported here of a NK/T-cell lymphoma in a 29 year old Indonesian man whom presented with an ulcer on the palate. The ulcer started on the pharynx and progressively involved the soft and hard palate. Eventually, the whole palate appeared necrosed with granulation tissue and the uvula was elongated and irregular.Immunohistochemical studies leads to the diagnosis of an extranodular NK/T cell lymphoma

\begin{tabular}{|c|l|}
\hline Author & Muhamad, H. M. ; Ibrahim, N. I. ; Zain, R. M. Z. \\
\hline Source & Oral Oncology \\
\hline ISSN & $1368-8375$ \\
\hline DOI & $10.1016 /$ j.oraloncology.2011.06.423 \\
\hline Volume & 47 \\
\hline Page & S132-S132 \\
\hline Year & 2011 \\
\hline
\end{tabular}

Keyword:

Oral squamous cell carcinoma, OSCC, lichenoid lesions, lichen planus, oral cancer, oral tumours, pemphigus, traumatic eosinophilic granuloma, aphthous ulcers, oral mucosal lesions, betel chewers mucosa, betel quid related lesions, betel quid, areca quid, tobacco quid, oral cancer screening, training and calibration, early detection, oral cancer awareness, biobanking, tissue bank, databank, oral cancer, tissue bank, research credibility, research ethics

Please Cite As:

MUHAMAD, H. M., IBRAHIM, N. I. \& ZAIN, R. M. Z. 2011. Immunohistochemical features of extra-nodal NK/T cell lymphoma. Oral Oncology, 47, S132-S132. 
URL:

- http://apps.webofknowledge.com >> Search Via Web of Science Accession No: 000292815100389

- http://www.sciencedirect.com/science/article/pii/S1368837511006294 